\title{
Recovery of Pt Surfaces for Ethylene Hydrogenation-Based Active Site Determination
}

\author{
Andras Sapi - Chris Thompson - Hailiang Wang • William D. Michalak • \\ Walter T. Ralston · Selim Alayoglu • Gabor A. Somorjai
}

Received: 27 November 2013/ Accepted: 5 May 2014

(C) Springer Science+Business Media New York 2014

\begin{abstract}
The effect of pretreatment $\left(\mathrm{O}_{2}\right.$ or $\left.\mathrm{H}_{2}\right)$ and catalyst history was investigated through room temperature ethylene hydrogenation reaction over several types of platinum based nanoparticle systems: $1.6 \mathrm{~nm}$ Pt/TTAB, $4.1 \mathrm{~nm} \mathrm{Pt} / \mathrm{PVP}$ (with and without UV treatment), $4.1 \mathrm{~nm} \mathrm{Pt}$ with a silica shell, and e-beam evaporated Pt thin films were tested. The $\mathrm{H}_{2}$ pretreatment resulted in the absence of activity. However, Pt active sites for the ethylene hydrogenation reaction were recovered after an $\mathrm{O}_{2}$ pretreatment irrespective of the catalyst history, regardless of the particle size nor the presence, absence or type of capping agent. The calculation of the average TOF resulted in $10.13 \pm$ 3.27. This value correlates well with data from the literature. Thus, the ethylene hydrogenation reaction can be used to determine available sites of Pt catalysts if the reaction is following an $\mathrm{O}_{2}$ pretreatment.
\end{abstract}

Keywords Heterogeneous catalysis - Ethylene hydrogenation $\cdot$ Platinum $\cdot$ Catalyst pretreatment

Electronic supplementary material The online version of this article (doi:10.1007/s10562-014-1272-y) contains supplementary material, which is available to authorized users.

A. Sapi · C. Thompson · H. Wang · W. D. Michalak ·

W. T. Ralston - S. Alayoglu · G. A. Somorjai $(\bowtie)$

Department of Chemistry, University of California, Berkeley, CA 94720, USA

e-mail: somorjai@berkeley.edu

A. Sapi - C. Thompson - H. Wang - W. D. Michalak ·

W. T. Ralston - S. Alayoglu - G. A. Somorjai

Materials Sciences and Chemical Sciences Divisions, Lawrence

Berkeley National Laboratory, Berkeley, CA 94720, USA

\section{Introduction}

Ethylene hydrogenation reaction has been extensively studied on single crystal Pt (111) [1-8] and Pt (100) [1,9] surfaces in the presence or absence of excess hydrogen both under ambient and ultra-high vacuum conditions. The $\mathrm{C}_{2} \mathrm{H}_{4}$ adsorption is structure-sensitive, however the overall ethylene hydrogenation reaction is structure-insensitive [1]. Under the conditions of 100 Torr of $\mathrm{H}_{2}, 35$ Torr of $\mathrm{C}_{2} \mathrm{H}_{4}, 625$ Torr of $\mathrm{He}$ and $295 \mathrm{~K}$, the $\mathrm{Pt}$ (111) surface is covered with ethylidyne, di- $\sigma$ bonded ethylene and $\pi$-bonded ethylene [2], as shown by sum frequency generation (SFG) vibrational spectroscopy experiments. The surface coverage of reactive, weakly adsorbed $\sigma$-bonded ethylene is only $\sim 4 \%$, however SFG spectra are not implicit indicators of activity [10].

Recently, several studies focused on the catalytic properties of Pt nanoparticles with different shapes and sizes [11-18]. Alayoglu et al. [14] showed that the turnover frequency of the ethylene hydrogenation reaction is insensitive to the size of the Pt nanoparticles in the range of 1-11 nm. However, slight differences were observed in the activity of $6 \mathrm{~nm}$ Pt spheres, octahedras, truncated octahedras and cubes.

Preparation of Pt nanoparticles are frequently based on the polyol process [19-22] which usually result in an organic capping layer covering the surface of the $\mathrm{Pt}$ nanoparticles after the synthesis [11, 22]. However, in the case of trimethyl tetradecyl ammonium bromide (TTAB) and polyvinlypyrrolidone (PVP), the capping layer has no effect on the intrinsic activity of the Pt catalysts in ethylene hydrogenation reaction [11].

Based on the structure insensitive nature of the ethylene hydrogenation reaction it can be used as a tool for determination of active Pt sites [14]. However, the number of active sites can change due to adsorbed species on the 
catalyst. Sum Frequency Generation Spectroscopy studies showed that the surface concentrations of the various adsorbed species are different in an ethylidyne precovered Pt (111) surface as compared to clean counterparts [2]. Zhu et al. [23] showed that the Pt (557) surface is covered by small platinum-oxide nanoparticles under $\sim 950$ mtorr of $\mathrm{O}_{2}$ which can be fully removed with a 43 mtorr $\mathrm{H}_{2}$ co-feed producing the clean $\mathrm{Pt}$ (557) surface. The history of the metal surface has a strong influence on the surface species and subsequent reactions.

In this study, we investigated the effect of $\mathrm{H}_{2}$ and/or $\mathrm{O}_{2}$ treatment at elevated temperatures on various platinumbased catalysts" activity in room temperature ethylene hydrogenation. We tested platinum nanoparticles with different capping agents (PVP, TTAB and $\mathrm{SiO}_{2}$ ) and with different sizes (1.6 and $4.1 \mathrm{~nm}$ ). We also investigated the influence of removal of the capping agent with UV treatment and with calcination at $550{ }^{\circ} \mathrm{C}$. Pt thin films prepared by e-beam evaporation were also tested. All the catalysts were active in ethylene hydrogenation conducted at room temperature. $\mathrm{A} \mathrm{H}_{2}$ pretreatment at $170{ }^{\circ} \mathrm{C}$ resulted in the dramatic loss of the catalytic activity. A following $\mathrm{O}_{2}$ pretreatment at $170{ }^{\circ} \mathrm{C}$ recovers the active sites for ethylene hydrogenation regardless of platinum size, type of capping agent, the presence or absence of such coating and the history of the catalyst. We probed the surface of $4.1 \mathrm{~nm}$ platinum nanoparticles with SFG vibrational spectroscopy under reaction conditions before and after the different pretreatment procedures. These studies show that ethylene or surface adsorbates are well observable on the platinum surface during the initial ethylene hydrogenation. After $\mathrm{H}_{2}$ pretreatment ethylene species were not observed. However, the $\mathrm{O}_{2}$ treatment resulted in SFG features in the $2800-3050 \mathrm{~cm}^{-1}$ region corresponding to ethylene surface species under reaction condition. This work shows the importance of the pretreatment and history of the catalyst on the subsequent reaction and gives a general method to recover Pt surfaces for available site determination based on the ethylene hydrogenation reaction.

\section{Experimental}

\subsection{Synthesis of PVP-Capped 4.1 nm Pt Nanoparticles} (Pt/PVP)

Hexachloroplatinic acid $\left(\mathrm{H}_{2} \mathrm{PtCl}_{6} \cdot 6 \mathrm{H}_{2} \mathrm{O}\right), \mathrm{PVP}\left(\mathrm{M}_{\mathrm{w}}=29\right.$ 000), TTAB, ethylene glycol (EG), tetraethylorthosilicate (TEOS) and hexane was purchased from Sigma-Aldrich and used without further purification.

$50 \mathrm{mg}$ of $\mathrm{H}_{2} \mathrm{PtCl}_{6} \cdot 6 \mathrm{H}_{2} \mathrm{O}$ and $220 \mathrm{mg}$ of PVP was dissolved in $5 \mathrm{ml} \mathrm{EG}$, separately. The solutions were mixed in a $25 \mathrm{ml}$ round bottom flask and refluxed at $160{ }^{\circ} \mathrm{C}$ for
60 min under Ar purging. As-obtained Pt nanoparticles were collected by precipitation with $40 \mathrm{ml}$ of acetone, followed by several washing cycles based on ethanol dispersion and hexane precipitation. The product was finally redispersed in $10 \mathrm{ml}$ ethanol.

Some of the samples were exposed to UV light in air prior to catalytic testing to remove the PVP capping shell. The method is described previously [22]. In brief, low pressure mercury $(\mathrm{Hg})$ lamps (Lights Sources Inc., GPH357T5VH/4P) are used as the UV source; the lamps emit at 184 and $254 \mathrm{~nm}$. The sample sat $1.2 \mathrm{~cm}$ below the lamps and was exposed to UV light for $3 \mathrm{~h}$ (Pt/ $P V P+U V)$.

\subsection{Synthesis of Silica-Capped $4.1 \mathrm{~nm} \mathrm{Pt}$ Nanoparticles $\left(\mathrm{Pt} / \mathrm{SiO}_{2}\right)$}

Core-shell NPs were made by dissolving $300 \mu \mathrm{L}$ of the Pt/ PVP suspension $\left(c_{\mathrm{Pt}}=1.6 \mathrm{mg} / \mathrm{mL}\right)$ and $5.0 \mu \mathrm{L}$ TEOS with $15 \mathrm{~mL}$ ethanol in a $20 \mathrm{~mL}$ glass scintillation vial. Subsequently, $2.25 \mathrm{~mL}$ of ammonium hydroxide $\left(\mathrm{NH}_{3} / \mathrm{H}_{2} \mathrm{O}\right)$ is added dropwise while the mixture is being stirred over a 5 min period. After all $\mathrm{NH}_{3} / \mathrm{H}_{2} \mathrm{O}$ is added, the mixture is left to sonicate for $2 \mathrm{~h}$. To separate the $\mathrm{Pt} / \mathrm{SiO}_{2}$ nanoparticles from the synthesis mixture, $\sim 6 \mathrm{~mL}$ acetone and $\sim 22 \mathrm{~mL}$ hexane were added and centrifuged at $4000 \mathrm{RPM}$ for $10 \mathrm{~min}$. $\mathrm{Pt} / \mathrm{PVP} / \mathrm{SiO}_{2}$ were washed two additional times by dissolution in $\sim 2 \mathrm{~mL}$ ethanol, precipitation in $\sim 12 \mathrm{~mL}$ hexane, and centrifugation.

In order to remove the organic capping agent, the $\mathrm{Pt}$ nanoparticles were calcined in air at $550{ }^{\circ} \mathrm{C}$ for $5 \mathrm{~h}$ in a tube furnace $\left(\mathrm{Pt} / \mathrm{SiO}_{2}\right.$, calcined $)$.

\subsection{Synthesis of $1.6 \mathrm{~nm}$ TTAB-Capped Pt Nanoparticles (Pt/TTAB)}

$2.5 \mathrm{~mL}$ of $20 \mathrm{mg} / \mathrm{mL} \mathrm{H}_{2} \mathrm{PtCl}_{6} \cdot 6 \mathrm{H}_{2} \mathrm{O}$ in $\mathrm{EG}$ was added to $2.5 \mathrm{~mL}$ of $20 \mathrm{mg} / \mathrm{mL} \mathrm{NaOH}$ in EG. The solution was heated to $160{ }^{\circ} \mathrm{C}$ and refluxed for $3 \mathrm{~h}$ under Ar. After cooling, $2.5 \mathrm{~mL}$ of $1 \mathrm{M}$ aqueous $\mathrm{HCl}$ was added to the obtained suspension and the nanoparticles were collected by centrifugation. The as-prepared particles were resonicated in $10 \mathrm{ml}$ of $6.7 \mathrm{mg} / \mathrm{mL}$ TTAB in ethanol. After hexane induced precipitation the product was redispersed in $10 \mathrm{~mL}$ ethanol.

\subsection{Preparation of Pt Thin Film}

Thin-film platinum catalyst samples were deposited onto quartz slide (Chemglass Life Sciences) using electron beam evaporation. Base pressure for evaporation was less 
than $10^{-5}$ Torr. The thickness of the Pt thin film was measured to be $2 \mathrm{~nm}$ by a quartz crystal microbalance calibrated to the platinum density and the distance of the sample from the evaporation source.

\subsection{Electron Microscopy}

The various Pt-based catalysts were supported of $\mathrm{Cu}$ grids (Electron Microscopy Sciences) and imaged using a JEOL $2100 \mathrm{LaB}_{6}$ transmission electron microscope (TEM) operated at $200 \mathrm{kV}$.

\subsection{Kinetic Measurements}

Both ethylene hydrogenation and catalyst pretreatments were conducted in a gold-covered stainless steel batch reactor equipped with a boron nitride plate heater (Momentive Ltd.) for sample heating and a recirculation pump (Metal Bellows; MB-21) for gas mixing. Pt nanoparticles and silica-capped counterparts were laid on $\mathrm{Si}$ substrates (Addison engineering Inc.; thickness of $475-550 \mu \mathrm{m}$, $500 \mathrm{~nm}$ thermal oxide on the surface) with LangmuirBlodgett [24, 25] films or drop-casting [26] techniques from ethanol suspensions of the nanoparticles.

In a typical ethylene hydrogenation reaction $(\mathrm{EH})$ the sample was kept at $25^{\circ} \mathrm{C}$ and 100 torr of $\mathrm{H}_{2}, 10$ torr of ethylene and 660 torr of $\mathrm{He}$ was introduced consecutively into the reactor. The ethane formation was monitored by a flame ionization detector integrated into a gas chromatograph (HP 5890 series II.). The ethylene conversion was kept under $10 \%$ during the measurements.

During the catalyst pretreatment process (PT), 77 Torr of $\mathrm{H}_{2}$ or $\mathrm{O}_{2}$ and 693 Torr $\mathrm{He}$ was mixed in the reactor and the sample stage was heated to $170{ }^{\circ} \mathrm{C}$ and held for $10 \mathrm{~min}$. After the treatment, the sample was cooled down to room temperature and the chamber was evacuated before the following EH. The usual experimental sequence was as follows: $\mathrm{EH} \rightarrow \mathrm{H}_{2} \mathrm{PT} \rightarrow \mathrm{EH} \rightarrow \mathrm{O}_{2} \mathrm{PT} \rightarrow \mathrm{EH} \rightarrow \mathrm{H}_{2} \mathrm{PT} \rightarrow$ $\mathrm{EH} \rightarrow \mathrm{O}_{2} \mathrm{PT} \rightarrow \mathrm{EH}$. It is simple to assess reversibility and deactivation because the same sample is used in the sequence.

\subsection{Sum Frequency Generation}

Sum frequency generation (SFG) spectroscopy is only sensitive to a break in inversion symmetry which usually occurs at a surface or interface, making SFG a powerful tool for investigating catalyst surfaces, adsorbates and reaction intermediates under reaction conditions [27]. The SFG experiments were performed as described in an earlier paper [22]. In brief, a Nd:YAG laser (Leopard D-20, Continuum) was used with 20 ps pulses at a $20 \mathrm{~Hz}$ repetition rate. The excitation energy at the platinum surface monitored was $100 \mu \mathrm{J}$ for both IR and VIS beams. The infrared beam was tuned in the $2700-3600 \mathrm{~cm}^{-1}$ range. All experiments were performed in the ppp polarization combination.

2D films of PVP-capped $4.1 \mathrm{~nm}$ platinum nanoparticles (Pt/PVP) are laid directly on sapphire prisms achieved by Langmuir-Blodgett deposition for the SFG studies. The anchored particles were monitored with SFG under similar reaction conditions used in the kinetic measurements. In a typical experiment, a reactor-like chamber connected to the SFG cell was filled with 660 Torr of Ar, 100 Torr of $\mathrm{H}_{2}$ and 10 Torr of ethylene, consecutively. The surface of the nanoparticles were monitored with SFG after each gas introduction. Nanoparticles were treated as described above in the kinetic measurements chapter $\left(\mathrm{EH} \rightarrow \mathrm{H}_{2}\right.$ PT $\left.\rightarrow \mathrm{EH} \rightarrow \mathrm{O}_{2} \mathrm{PT} \rightarrow \mathrm{EH}\right)$.

\section{Results and Discussion}

TEM images of $4.1 \pm 0.7 \mathrm{~nm}$ Pt nanoparticles made by PVP-assisted polyol synthesis shows spherical particles with a narrow size distribution (Fig. 1a). The silica encapsulation resulted in Pt nanoparticles embedded into a foam-like silica frame structure (Fig. 1b). The morphology and size of the Pt nanoparticles is not changed during the capping reaction. The $\mathrm{NaOH}$-assisted synthesis afforded $\mathrm{Pt}$ nanoparticles with uniform size and a narrow size distribution $(1.6 \pm 0.3 \mathrm{~nm})$ as shown in Fig. 1c Pt thin film made by electron beam evaporation is not a continuous structure but a coherent system of tiny (1-2 nm) Pt nanoparticles coalesced into 3-8 membered nanoclusters (Fig. 1d).

Figure 2 shows the reaction rates of room temperature ethylene hydrogenation over the Pt-based catalysts immediately after $\mathrm{O}_{2}$ pretreatment process at $170{ }^{\circ} \mathrm{C}$ for $10 \mathrm{~min}$. The calculation of the turnover rates shown in Fig. 2 was based on the nanoparticle coverage of the Si wafer surface determined from SEM and TEM images, assuming that each $\mathrm{Pt}$ atom at the monolayer surface is an available site ${ }^{1}$.

\footnotetext{
${ }_{1}^{1}$ In the case of the $4.1 \mathrm{~nm} \mathrm{Pt} / \mathrm{PVP}, 4.1 \mathrm{~nm} \mathrm{Pt} / \mathrm{PVP}+\mathrm{UV}$, and $1.6 \mathrm{~nm}$ Pt/TTAB samples, the surface area of the silica wafer used in the catalytic tests covered by Pt was determined from SEM images. In the case of the Pt e-beam sample, TEM images were used (Supporting information). The number of Pt nanoparticles was calculated from the Pt covered surface area by using the average particle diameter resulted from TEM images (Fig. 1). The number of active sites was estimated using the number of $\mathrm{Pt}$ atoms on the Pt nanoparticles" surface. We assumed that the nanoparticles are spheres and have $\mathrm{Pt}$ (111) fcc surfaces with a unit cell size of $3.92 \AA$ and two atoms/ surface of unit cell. The equation for TOF calculation is as follows: $\mathrm{TOF}=\mathrm{rEH} /(\mathrm{AS} \cdot \mathrm{rC}, \mathrm{LR} /(\mathrm{AD}) \cdot \mathrm{NAS}) \mathrm{NAS}=\mathrm{ANP}^{*}(2 / 3.92 \AA)$ Where ' $\mathrm{rEH}$ ' is the rate of ethylene hydrogenation, 'AS' is the size of the silica wafer used in catalytic tests, 'rC,LR' is the Pt covered surface area of the silica wafer estimated from SEM images, 'AD' is the cross
} 

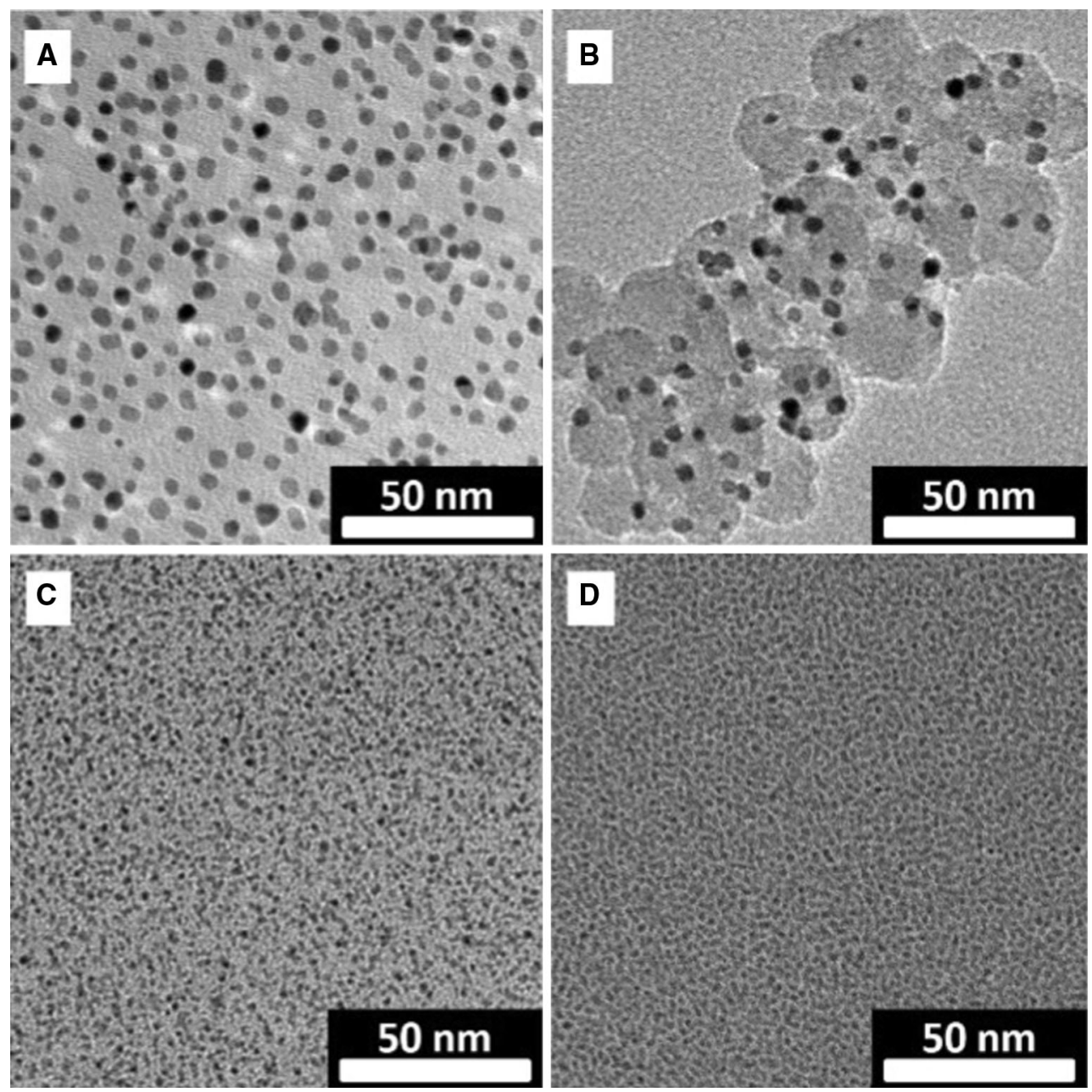

Fig. 1 Typical TEM images of the $4.1 \pm 0.7 \mathrm{~nm}$ Pt nanoparticles (a) and $\mathrm{SiO}_{2}$-embedded counterparts (b); $1.6 \pm 0.3 \mathrm{~nm}$ Pt nanoparticles (c) and Pt thin film made by e-beam evaporation (d)

The calculation of the average TOF-which included all the tested catalysts after the $\mathrm{O}_{2}$ pretreatment-resulted in $10.13 \pm 3.27$. This value correlates well with data from the literature as shown in the additional blue columns (Fig. 2) corresponding to ethylene hydrogenation results conducted under similar reaction conditions $\left(35\right.$ torr $\mathrm{C}_{2} \mathrm{H}_{4}, 100$ torr $\mathrm{H}_{2}, 625$ torr $\mathrm{He}, 25^{\circ} \mathrm{C}$ ) over $\mathrm{Pt}$ (111) and $\mathrm{Pt}$ (100) single crystal surfaces [1] and supported platinum catalysts made by the incipient wetness/impregnation method $(1 \% \mathrm{Pt} /$ $\mathrm{SiO}_{2}, 1 \% \mathrm{Pt} / \mathrm{TiO}_{2}$ ) [28]. This study shows that the number

\section{Footnote 1 continued}

section of an individual Pt nanoparticle, 'NAS' is the number of the available sites on an individual Pt nanoparticle, 'ANP' is the surface area of an individual Pt nanoparticle. To determine the active sites of $\mathrm{Pt} / \mathrm{SiO} 2$ and $\mathrm{Pt} / \mathrm{SiO} 2$, calcined samples similar calculations were performed. Herein, we used an estimation based on the $\mathrm{Pt} / \mathrm{SiO} 2$ concentration of the silica wafer from the SEM images (Supporting information). The ratio of the capping $\mathrm{SiO} 2$ and the $\mathrm{Pt}$ nanoparticles was calculated from the synthesis parameters (amount of TEOS and $4.1 \mathrm{~nm}$ Pt nanoparticles) of $\mathrm{Pt}$ active sites for ethylene hydrogenation is recovered after the $\mathrm{O}_{2}$ pretreatment irrespective of the catalyst history, regardless of the particle size nor the presence, absence or type of capping agent. Thus, the ethylene hydrogenation reaction can be used to determine available sites of Pt catalysts following the $\mathrm{O}_{2}$ pretreatment as described above. The low TOF value related to the $1.6 \mathrm{~nm}$ $\mathrm{Pt} / \mathrm{TTAB}$ sample can be attributed to the uncertainty of the Pt particle concentration determination arising from the limitation of the SEM imaging.

Figure 3 shows the catalytic activity of various Pt catalysts for the ethylene hydrogenation reaction after the different $\mathrm{O}_{2}$ or $\mathrm{H}_{2}$ pretreatment procedures. There is a dramatic effect of elevated temperature pretreatment on the subsequent ethylene hydrogenation reaction. After the first $\mathrm{H}_{2}$ pretreatment at $170{ }^{\circ} \mathrm{C}$ the catalytic activity significantly declined in the case of all Pt-based catalysts. Radiotracer and TPD studies showed that $\mathrm{C}^{14}$-labeled ethylene chemisorbed on $\mathrm{Pt}$ (111) surfaces can dehydrogenate to 


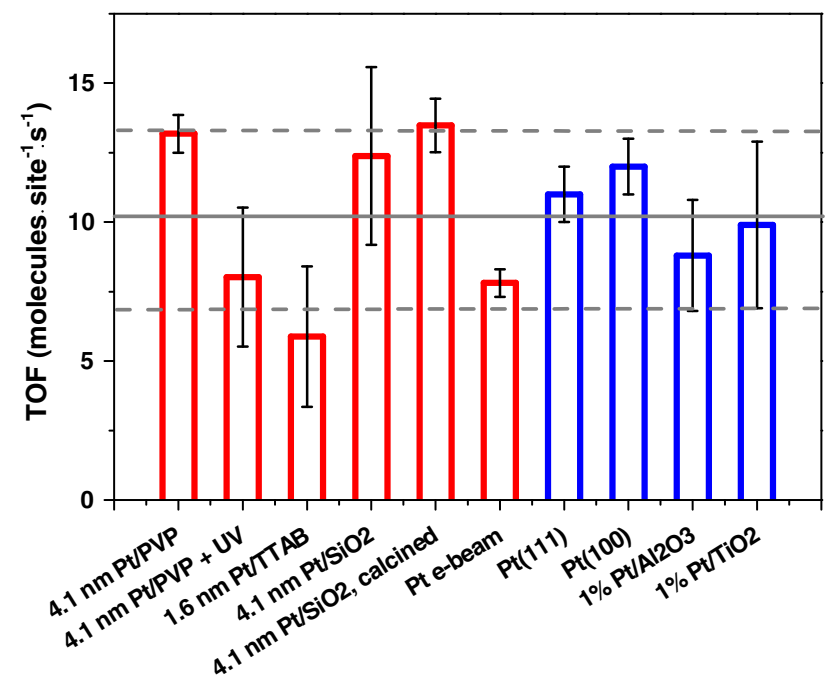

Fig. 2 Catalytic activity of the different Pt catalysts in the ethylene hydrogenation reaction after $\mathrm{O}_{2}$ pretreatment $\left(77\right.$ torr $\mathrm{O}_{2}, 693$ torr $\mathrm{He})$ at $170{ }^{\circ} \mathrm{C}$ for $10 \mathrm{~min}$. The average of the TOFs obtained after the $\mathrm{O}_{2}$ pretreatment was $10.13 \pm 3.27$. The results correlate well with data from literature (blue columns). Platinum active sites for the ethylene hydrogenation reaction have been recovered irrespective of the history or morphology of the catalyst

form $\mathrm{CH}_{2}, \mathrm{CH}, \mathrm{C}_{2} \mathrm{H}$ or other carbon-rich fragments at this temperature [29]. However, carbon-rich fragments can be formed in a higher concentration at lower temperature and under ethylene-rich atmosphere (under reaction condition $\sim 96 \%$ of the surface is covered by ethylidine [2]), the quality and mobility of species formed at higher temperature under $\mathrm{H}_{2}$ atmosphere is different. Such surface intermediates lose their mobility and deactivate the metal surface by blocking the active sites for the reaction (e.g. polymerization [10]) even if they may exist in a low concentration on the surface. Several studies showed that trace amount of surface contamination can lead to the total inactivity of the metal surface [30, 31].

The $\mathrm{O}_{2}$ pretreatment resulted in the recovery of the blocked Pt active sites in ethylene hydrogenation. In the case of $\mathrm{Pt} / \mathrm{PVP}, \mathrm{Pt} / \mathrm{PVP}+\mathrm{UV}, \mathrm{Pt} / \mathrm{SiO}_{2}$ and e-beam deposited thin film the activities were close to the initial values. After a following cycle of $\mathrm{H}_{2}$ and $\mathrm{O}_{2}$ pretreatment afforded similar results as the first treatment processes. After the $\mathrm{H}_{2}$ pretreatment the activity was significantly lowered but was revitalized by the $\mathrm{O}_{2}$ pretreatment.

Kinetic results correlate with spectral features of SFG vibrational spectroscopy. Figure 4 shows SFG spectra of PVP-capped $4.1 \mathrm{~nm}$ platinum nanoparticle monolayer films after $3 \mathrm{~h}$ of UV irradiation. PVP is almost completely removed after UV treatment [22], which makes it less likely that the vibrational features of PVP interfere with reaction intermediates of interest. Although UV light does degrade PVP, Pt nanoparticles should not be considered free of carbonaceous deposits. In the presence of ethylene and $\mathrm{H}_{2}$ (black signs), dominant peaks at $2875 \mathrm{~cm}^{-1}$ (1) and a smaller peak at $2910 \mathrm{~cm}^{-1}$ (2) appear in the spectrum. These peaks can be attributed to ethylene surface adsorbates ethylidyne and di- $\sigma$ ethylene, respectively [2]. Because of the low adsorption energy of ethane and the high wavenumber stretch of ethylene vibrations $\left(>2990 \mathrm{~cm}^{-1}\right.$ ), the vibrations observed at 2875 and $2910 \mathrm{~cm}^{-1}$ must be due to surface species (not products or

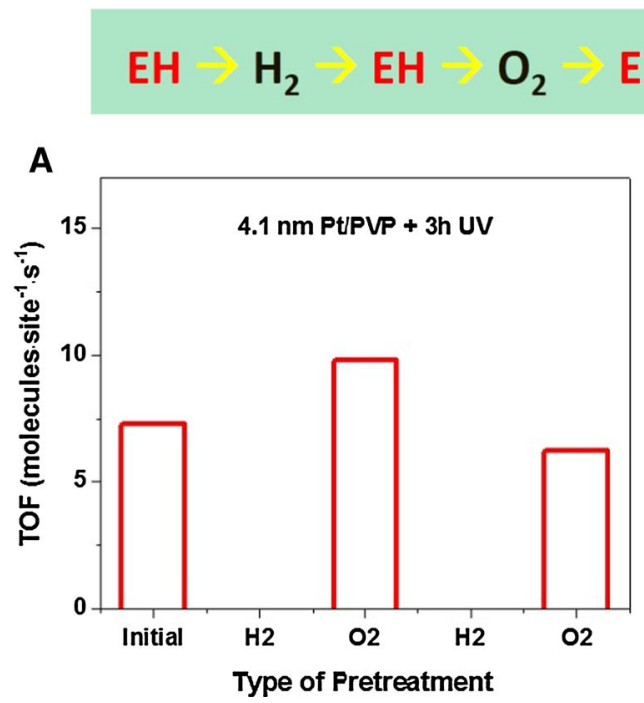

Fig. 3 The effect of the pretreatment on ethylene hydrogenation over UV-treated $4.1 \mathrm{~nm}$ Pt/PVP Pt sample (a). The ethylene hydrogenation reaction was conducted at $25{ }^{\circ} \mathrm{C}$ with 10 torr $\mathrm{C}_{2} \mathrm{H}_{4}$ and 100 torr $\mathrm{H}_{2}$ balanced with $\mathrm{He}$ to 770 torr. In the case of the pretreatment processes, 77 torr $\mathrm{H}_{2}$ or $\mathrm{O}_{2}$ in 693 torr $\mathrm{He}$ was introduced to the

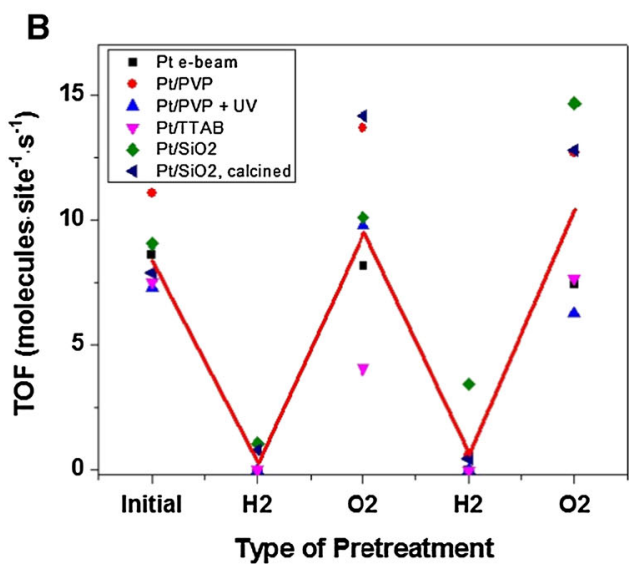

sample at $170{ }^{\circ} \mathrm{C}$ for $10 \mathrm{~min}$. The $\mathrm{H}_{2}$ pretreatment resulted in a dramatic deactivation of the tested catalyst. After $\mathrm{O}_{2}$ pretreatment the activity is regained. Subsequent cycles of $\mathrm{EH} \rightarrow \mathrm{H}_{2} \mathrm{PT} \rightarrow \mathrm{EH} \rightarrow \mathrm{O}_{2}$ $\mathrm{PT} \rightarrow \mathrm{EH}$ shows similar results. This phenomenon is general to all types of Pt-based catalysts tested in this study (b) 


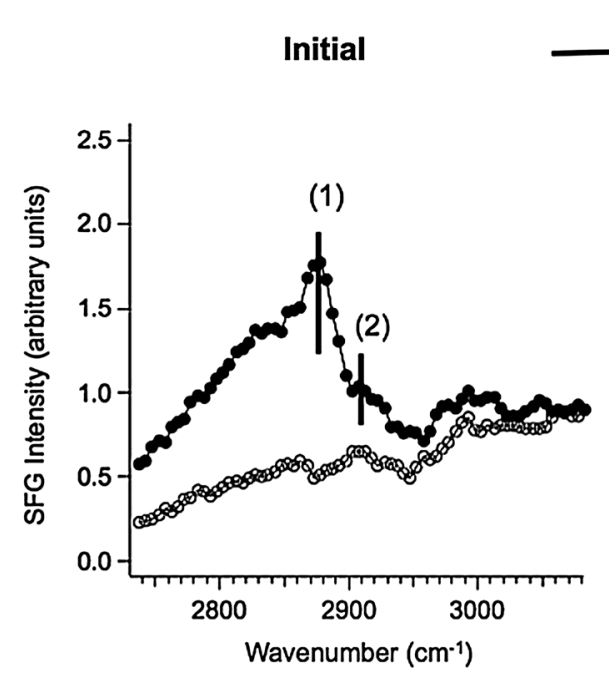

$\mathrm{H}_{2} \longrightarrow \mathrm{O}_{2}$
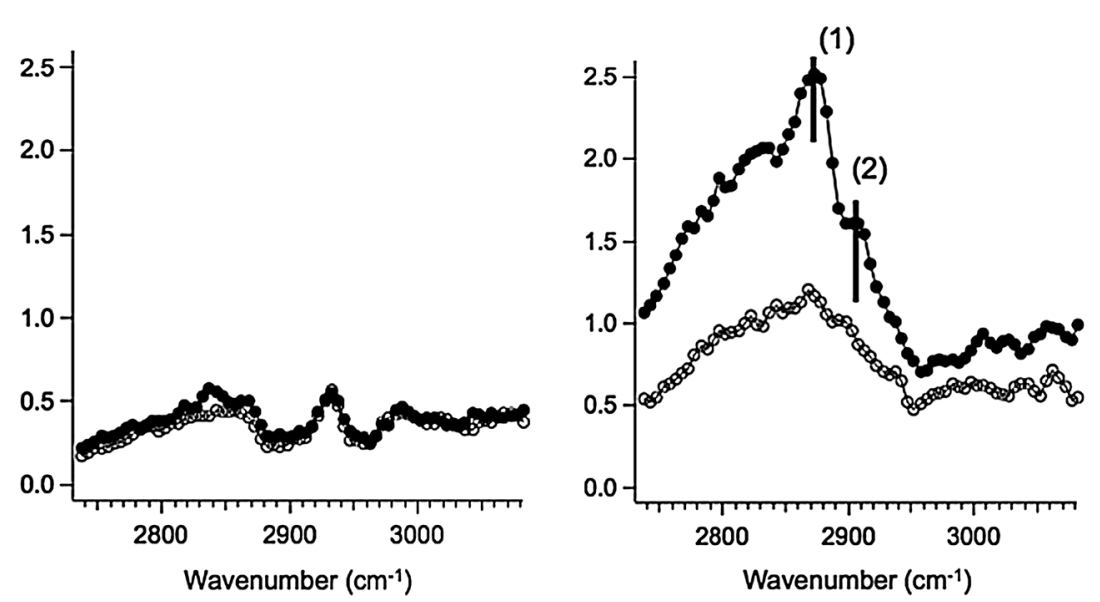

Fig. 4 SFG spectra of the PVP-capped $4.1 \mathrm{~nm}$ Pt nanopartcicles after $3 \mathrm{~h}$ UV treatment (Pt-PVP + UV) under reaction conditions before and after reductive and oxidative treatment processes. Grey refers to background spectra of 660 torr of $\mathrm{Ar}$ and 100 torr of $\mathrm{H}_{2}$; black shows the spectra after addition of 10 torr of ethylene. At the initial stage peaks at $2875 \mathrm{~cm}^{-1}$ (1) and $2910 \mathrm{~cm}^{-1}$ (2) belonging to ethylidyne

reactants). The vibrational features shown here are similar to those published previously on $\mathrm{Pt}$ (111) [10].

After $\mathrm{H}_{2}$ pretreatment at $170{ }^{\circ} \mathrm{C}$ no significant activity is observed under the ethylene hydrogenation reaction condition. The lack of ethylene adsorbates in the SFG spectra correlate well with the sharp decrease in catalytic activity. In this case, it appears ethylene cannot adsorb on the Pt surface due to the blocking effect of the hydrocarbon species which themselves appear to have no significant SFG features. Following the $\mathrm{O}_{2}$ pretreatment, the peaks previously assigned to ethylidyne and di- $\sigma$ ethylene (2875 and $2910 \mathrm{~cm}^{-1}$ ) reappear in the SFG spectrum obtained in the ethylene/ $/ \mathrm{H}_{2}$ mixture. The appearance of such features correlate well with the increased catalytic activity (Fig. 3).

In order to investigate the origin of the blocking adsorbates, the initial ethylene hydrogenation step was eliminated. The $4.1 \mathrm{~nm} \mathrm{Pt/PVP} \mathrm{sample} \mathrm{was} \mathrm{first} \mathrm{treated} \mathrm{in}$ $\mathrm{H}_{2}$ at $170{ }^{\circ} \mathrm{C}$ for $10 \mathrm{~min}$. The catalytic activity based on the room temperature ethylene hydrogenation reaction is shown on Fig. 5a (the values of the relative rates are showing the catalytic activity compared to the highest activity measured in the same experimental cycle). Pt/PVP sample shows no activity after the initial $\mathrm{H}_{2}$ pretreatment indicating the fact that the dramatic activity loss does not just originate from the adsorbates resulting from ethylene hydrogenation. The catalytic activity reappears after the $\mathrm{O}_{2}$ pretreatment similar to the above mentioned experiments indicating the revitalization effect of the $\mathrm{O}_{2}$ pretreatment. The deactivation is also observed after an $\mathrm{O}_{2}-\mathrm{H}_{2}$ pretreatment cycle (Fig. 5, pretreatment $\mathrm{O}_{2} \rightarrow \mathrm{H}_{2}$ ) even if and di- $\sigma$ ethylene, respectively indicate the presence of ethylene adsorbates on the platinum surface. After $\mathrm{H}_{2}$ pretreatment, there is no detectable ethylene adsorption, while ethylene adsorbates are observed under the ethylene hydrogenation conditions after oxygen pretreatment

there was no ethylene hydrogenation conducted in-between those two processes showing that the surface is not liberated from adsorbed species. These adsorbates are blocking the active surface sites after $\mathrm{H}_{2}$ pretreatment, while these sites are accessible after $\mathrm{O}_{2}$ pretreatment.

In order to remove PVP and other hydrocarbons from the surface, the " $\mathrm{Pt} / \mathrm{SiO}_{2}$, calcined" sample was pretreated in the reaction chamber under 10 torr of $\mathrm{O}_{2}$ for $2 \mathrm{~h}$ at $350{ }^{\circ} \mathrm{C}$ immediately before the experiments. Catalytic activity was observed after the first $\mathrm{H}_{2}$ pretreatment (Fig. 5b) showing the accessibility of the active sites, which remains stable after subsequent $\mathrm{O}_{2}$ pretreatment. However, after ethylene hydrogenation was performed the $\mathrm{H}_{2}$ pretreatment resulted in the dramatic loss of activity in the ethylene hydrogenation reaction similar as described above. The significant differences in this initial $\mathrm{O}_{2}$ at $350{ }^{\circ} \mathrm{C}$ treatment compared to the behavior of the previously tested catalysts implicates the PVP or other hydrocarbons and their fragments on the $\mathrm{Pt}$ surface in the deactivation of the catalysts after $\mathrm{H}_{2}$ pretreatment. However, regardless of the adsorbed hydrocarbon the available $\mathrm{Pt}$ sites for the ethylene hydrogenation reaction can be recovered with $\mathrm{O}_{2}$ pretreatment at $170{ }^{\circ} \mathrm{C}$.

To further confirm the effect of preadsorbed hydrocarbons on the catalytic activity, 10 torr of hexane was introduced to the "Pt/SiO${ }_{2}$, calcined" sample after an initial treatment under 10 torr of $\mathrm{O}_{2}$ for $2 \mathrm{~h}$ at $350{ }^{\circ} \mathrm{C}$. After evacuation and the first $\mathrm{H}_{2}$ pretreatment process no catalytic activity was observed showing the blocking effect of adsorbed hexane and derivatives on the surface (Fig. 5c). 

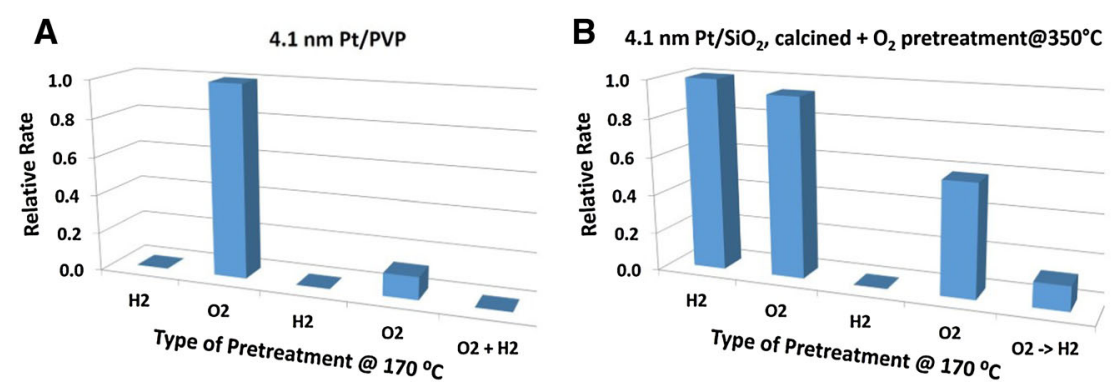

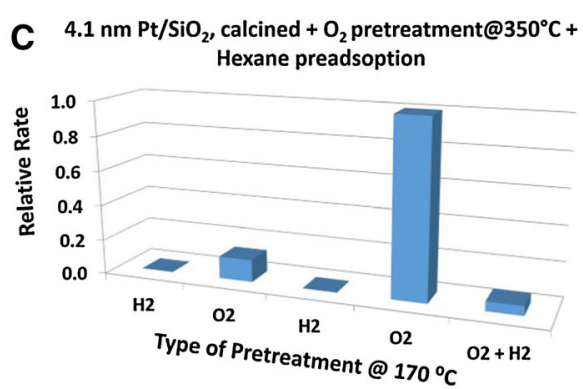

Fig. 5 The effect of the pretreatment on room temperature ethylene hydrogenation after an initial $\mathrm{H}_{2}$ pretreatment at $170{ }^{\circ} \mathrm{C}$ over (a) raw $4.1 \mathrm{~nm} \mathrm{Pt} / \mathrm{PVP}$; (b) $\mathrm{Pt} / \mathrm{SiO}_{2}$, calcined sample after preoxidation at $350{ }^{\circ} \mathrm{C}$ under 10 torr of $\mathrm{O}_{2}$ for $2 \mathrm{~h}$; (c) $\mathrm{Pt} / \mathrm{SiO}_{2}$, calcined sample after

The first $\mathrm{O}_{2}$ pretreatment resulted in the accessibility of $\mathrm{Pt}$ active sites in the ethylene hydrogenation reaction. Hence, the results show that the catalytic activity dramatically depends on the history of the catalysts. However, $\mathrm{O}_{2}$ pretreatment at $170{ }^{\circ} \mathrm{C}$ can regain catalytic activity in room temperature ethylene hydrogenation reactions without reference to the surface history.

\section{Conclusion}

We studied the catalytic activity of Pt nanoparticles with different sizes (1.6 and $4.1 \mathrm{~nm}$ ) with and without capping agents (PVP and TTAB), in the presence or absence of silica capping as well as electron beam evaporated thin $\mathrm{Pt}$ films in room temperature ethylene hydrogenation reactions after both $\mathrm{H}_{2}$ and $\mathrm{O}_{2}$ pretreatments at elevated temperatures. After $\mathrm{H}_{2}$ pretreatment at $170{ }^{\circ} \mathrm{C}$ the catalytic activity significantly declined in the case of all the Pt-based catalysts. We attribute this phenomenon to surface adsorbates blocking the available sites for the ethylene hydrogenation reaction.

Available $\mathrm{Pt}$ sites for ethylene hydrogenation are recovered after the $\mathrm{O}_{2}$ pretreatment irrespective of the catalyst history, regardless of the particle size nor the presence, absence or type of capping agent. Calculation of the average TOF over all the tested catalysts resulted in $10.13 \pm 3.27$, in agreement with previous values from literature. Thus, the ethylene hydrogenation reaction can be used to determine available sites of Pt catalysts following an $\mathrm{O}_{2}$ pretreatment.

SFG results under ethylene hydrogenation reaction conditions showed that no ethylene adsorbates were present on the $4.1 \mathrm{~nm}$ platinum nanoparticle surface after the $\mathrm{H}_{2}$ pretreatment. However, ethylene surface adsorbates were observed on the platinum surface after the $\mathrm{O}_{2}$ pretreatment.

$\mathrm{H}_{2}$ treatment resulted in the loss of catalytic activity in the ethylene hydrogenation reaction on $\mathrm{Pt}$ surfaces preoxidation at $350{ }^{\circ} \mathrm{C}$ under 10 torr of $\mathrm{O}_{2}$ for $2 \mathrm{~h}$ followed by room temperature hexane (10 torr) adsorption for $10 \mathrm{~min}$ before chamber evacuation

predosed with hydrocarbons (i.e. ethylene, hexane). This is also true for ligand capped (i.e. PVP) Pt nanoparticle surfaces. However, the intrinsic ethylene hydrogenation rates were restored after the preliminary $\mathrm{O}_{2}$ pretreatment.

Acknowledgments This work was supported the Director, Office of Basic Energy Sciences, Material Sciences and Engineering Division U.S. Department of Energy, under Contract DE-AC02-05CH11231.

\section{References}

1. McCrea KR, Somorjai GA (2000) J Mol Catal A 163:43-53

2. Cremer PS, Su XC, Shen YR, Somorjai GA (1996) J Am Chem Soc 118:2942-2949

3. Cremer PS, Su XC, Shen YR, Somorjai GA (1996) Catal Lett 40:143-145

4. Tilekaratne A, Simonovis JP, Fagundez MFL, Ebrahimi M, Zaera F (2012) ACS Catal 2:2259-2268

5. Chen Y, Vlachos DG (2010) J Phys Chem C 114:4973-4982

6. Miura T, Kobayashi H, Domen K (2000) J Phys Chem B 104:6809-6814

7. Ofner H, Zaera F (1997) J Phys Chem B 101:396-408

8. Zaera F (1990) J Phys Chem 94:5090-5095

9. Backman AL, Masel RI (1988) J Vac Sci Tech A 6:1137-1139

10. Somorjai GA, Li Y (2010) Introduction to surface chemistry and catalysis. Wiley, New York

11. Kuhn JN, Tsung CK, Huang W, Somorjai GA (2009) J Catal 265:209-215

12. Kliewer CJ, Aliaga C, Bieri M, Huang W, Tsung CK, Wood JB, Komvopoulos K, Somorjai GA (2010) J Am Chem Soc 132:13088-13095

13. Aliaga C, Tsung CK, Alayoglu S, Komvopoulos K, Peidong Y, Somorjai GA (2011) J Phys Chem C 115:8104-8109

14. Alayoglu S, Aliaga C, Sprung C, Somorjai GA (2011) Catal Lett 141:914-924

15. Rioux RM, Song H, Hoefelmeyer JD, Yang P, Somorjai GA (2005) J Phys Chem C 109:2192-2202

16. Shao MH, Peles A, Shoemaker K (2011) Nano Lett 11:3714-3719

17. Liu SH, Wu MT, Lai YH, Chiang CC, Yu NY, Liu SB (2011) J Mater Chem 21:12489-12496

18. Li Y, Petroski J, El-Sayed MA (2000) J Phys Chem B 104:10956-10959 
19. Kakati N, Lee SH, Maiti J, Yoon YS (2012) Surf Sci 606: $1633-1637$

20. Yin J, Wang JH, Li MR, Jin CZ, Zhang T (2012) Chem Mater 24:2645-2654

21. Cho SJ, Ouyang JY (2011) J Phys Chem C 115:8519-8526

22. Baker LR, Kennedy G, Krier JM, Spronsen MV, Onorato RM, Somorjai GA (2012) Catal Lett 142:1286-1294

23. Zhu Z, Melaet G, Axnanda S, Alayoglu S, Liu Z, Salmeron M, Somorjai GA (2013) J Am Chem Soc 135:12560-12563

24. Song H, Kim F, Connor S, Somorjai GA, Yang P (2005) J Phys Chem B 109(1):188-193

25. Bratlie KM, Komvopoulos K, Somorjai GA (2008) J Phys Chem C 112:11865
26. Wang H, Wang Y, Zhu Z, Sapi A, Kwangjin A, Kennedy G, Michalak WD, Somorjai GA (2013) Nano Lett 13:2976-2979

27. Shen YR (2003) The principles of nonlinear optics. Wiley, New york

28. Pazmino HJ, Bai C, Miller TJ, Ribeiro HF, Delgass NW (2013) Catal Lett 143:1098-1107

29. Davis SM, Zaera F, Gordon BE, Somorjai GA (1985) J Catal 92:240-246

30. Iablokov V, Beaumount SK, Alayoglu S, Pushkarev VV, Specht C, Gao J, Alivisatos PA, Kruse N, Somorjai GA (2012) Nano Lett 12:3091-3096

31. Goodman DW (1984) Appl Surf Sci 19:1-13 